J. Dairy Sci. 99:8561-8570

http://dx.doi.org/10.3168/jds.2016-11248

(C) 2016, THE AUTHORS. Published by FASS and Elsevier Inc. on behalf

of the American Dairy Science Association ${ }^{\circledR}$. This is an open access article under

the CC BY-NC-ND license (http://creativecommons.org/licenses/by-nc-nd/3.0/).

\title{
Prediction of fatty acid chain length and unsaturation of milk fat by mid-infrared milk analysis ${ }^{1}$
}

\author{
Karen L. Wojciechowski and David M. Barbano ${ }^{2}$ \\ Department of Food Science, Northeast Dairy Foods Research Center, Cornell University, Ithaca, NY 14853
}

\begin{abstract}
Our objective was to develop partial least squares (PLS) models to predict fatty acid chain length and total unsaturation of milk fat directly from a mid-infrared (MIR) spectra of milk at $40^{\circ} \mathrm{C}$ and then determine the feasibility of using those measures as correction factors to improve the accuracy of milk fat determination. A set of 268 milks (modified milks, farm bulk tank milks, and individual cow) were analyzed for fat, true protein, and anhydrous lactose with chemical reference methods, and in addition a MIR absorption spectra was collected for each milk. Fat was extracted from another portion of each milk, the fat was saponified to produce free fatty acids, and the free fatty acids were converted to methyl esters and quantified using gas-liquid chromatography. The PLS models for predicting the average chain length (carbons per fatty acid) and unsaturation (double bonds per fatty acid) of fatty acids in the fat portion of a milk sample from a MIR milk spectra were developed and validated. The validation performance of the prediction model for chain length and unsaturation had a relative standard deviation of 0.43 and $3.3 \%$, respectively. These measures are unique in that they are fat concentration independent characteristics of fat structure that were predicted directly with transmission MIR analysis of milk. Next, the real-time data output from the MIR spectrophotometer for fatty acid chain length and unsaturation of milk were used to correct the fat $\mathrm{A}(\mathrm{C}=\mathrm{O}$ stretch $)$ and fat $\mathrm{B}(\mathrm{C}-\mathrm{H}$ stretch $)$ measures to improve accuracy of fat prediction. The accuracy validation was done over a period of 5 mo with 12 sets of 10 individual farm milks that were not a part of the PLS modeling population. The correction of a traditional fat $\mathrm{B}$ virtual filter result $(\mathrm{C}-\mathrm{H}$ stretch) for sample-to-sample variation in unsaturation reduced
\end{abstract}

Received April 1, 2016.

Accepted July 18, 2016.

${ }^{1}$ Use of names, names of ingredients, and identification of specific models of equipment is for scientific clarity and does not constitute any endorsement of product by the authors, Cornell University, or the Northeast Dairy Foods Research Center.

${ }^{2}$ Corresponding author: dmb37@cornell.edu

the Euclidean distance for predicted fat from 0.034 to 0.025. The correction of a traditional fat A virtual filter result $(\mathrm{C}=\mathrm{O}$ stretch $)$ modified with additional information on sample-to-sample variation of chain length and unsaturation gave the largest improvement (reduced Euclidean distance from 0.072 to 0.016 ) and the best validation accuracy (i.e., lowest Euclidean distance) of all the fat prediction methods.

Key words: mid-infrared, carbon number, unsaturation

\section{INTRODUCTION}

Mid-infrared (MIR) transmission spectrophotometry is used for both milk payment testing and dairy herd improvement record keeping worldwide. The accuracy of measurement of fat and protein content of milk is extremely important because it has a direct effect on the payment to individual dairy farmers (Lynch et al., 2004; Barbano and Lynch, 2006). Development of harmonized protocols for interlaboratory studies aided in the improvement of method performance and provided a harmonized set method performance statistics (AOAC, 1989; AOAC International, 1995) that provide metrics of expected method performance. The practical interpretation of statistical metrics of method performance parameters was described by Lynch (1998). As farms in the United States have increased in size, the effect of small errors in testing have a large financial effect when applied to large milk volumes. Therefore, continued improvement of the accuracy of milk fat and protein testing become more important as farms get larger and when the value of milk fat and protein are high. Historically, the measurement of fat by MIR has used the carbonyl stretch $(\mathrm{C}=\mathrm{O})$, which has been called fat $\mathrm{A}$, and the symmetrical carbon hydrogen stretch $(\mathrm{C}-\mathrm{H})$, which has been called fat $\mathrm{B}$ in the MIR region (Biggs et al., 1987; Barbano and Clark, 1989).

Kaylegian et al. (2009a) demonstrated that sampleto-sample differences between MIR predictions of fat content of a milk and the ether extraction reference analysis of the same sample are explained by sampleto-sample variation in the differences in mean fatty acid chain length (CL) and mean unsaturation (UN) 
of the milk fat. The CL and UN of milk fat can vary systematically among farms due to differences in feeding and management, and these differences can produce systematic over- or underestimation of milk fat content for a farm. The magnitude of the error in fat estimate for an individual farm milk increases as a function of the difference between the average CL and UN of the individual farm milk and the mean of the set of milks used to calibrate (i.e., adjust slope and intercept) the specific infrared milk analyzer being used. Kaylegian et al. (2009a) reported a range of mean fatty acid CL across 45 farms from 13.83 to 15.06 carbons and a range of mean fatty acid UN from 0.25 to 0.42 double bonds per fatty acid. This range in CL and UN can cause systematic errors of $\pm 0.1 \%$ fat relative to the ether extraction reference value on a milk sample from an individual farm.

A description of basic calibration equations (Barbano and Clark, 1989; Lynch et al., 2006) and reference and sample wavelengths used for measurement was provided by Kaylegian et al. (2009b). The traditional fat A and fat B measurements can be made either with optical filters or with virtual filters produced from a Fourier transform MIR spectra. With time, optical-filter-based MIR milk analyzers are being replaced with MIR spectrophotometers. The MIR spectrophotometers can be used with optimized virtual filter versions of the traditional fat $\mathrm{A}$ and fat $\mathrm{B}$ wavelengths (Kaylegian et al., 2009b), or spectral prediction models for fat and protein can be produced by partial least squares (PLS) statistical modeling (Luinge et al., 1993). When the traditional MIR filter models are set up and managed correctly, they provide excellent and reliable performance for measurement of the major components of milk and are easier for the instrument operator to understand than PLS models. The PLS models are generally developed by each equipment manufacturer and provide more of a "black box" approach to MIR milk testing. The PLS prediction models can differ in performance from one equipment manufacturer to another; they can differ in their sensitivity to variation in homogenizer performance, preservative type and concentration, and sample temperature variation. Over the years the accuracy of MIR milk testing has been improved due to improved reference chemistry performance (Lynch et al., 1994, 1997), participation in routine proficiency testing for laboratories running reference chemistry, and more care being taken in producing sets of reference samples that have a better range of component concentrations with fewer high leverage samples (Kaylegian et al., 2006). Even with these improvements, there are still factors that vary in milk that cause fat reference chemistry values and instrument values not to agree. Kaylegian et al. (2009b) demonstrated the sen- sitivity of MIR fat measures to variation in fatty acid composition from sample to sample. Sample-to-sample variation in fatty acid CL and UN were identified as 2 factors that limit the accuracy of fat testing (Kaylegian et al., 2009a). Variation in fatty acid CL and UN in bulk tank milk is caused by variation in mean DIM for the herd due to variation in milk fatty acid composition caused by stage of lactation (Lynch et al., 1992), and the feeding of rumen bypass fat used in lactating dairy cattle feeding to increase the energy density of the diet for high-producing dairy cows.

Soyeurt et al. (2006) reported the development of PLS prediction models using MIR spectra to measure the concentration of a range of individual milk fatty acids and groups of fatty acids (e.g., saturated, monounsaturated, polyunsaturated) present in milk fat, expressed as grams of fatty acid per $100 \mathrm{~mL}$ of milk. De Marchi et al. (2014) reviewed and compared the performance of fatty acid prediction models reported in the literature. Ferrand-Calmels et al. (2014) expanded the use of MIR for milk fatty acid measurement to ewe and goat milks. We have not found any reports in the literature where MIR has been used to directly measure metrics of global fatty acid structure in milk. Our objective was to develop PLS models from MIR spectra to predict fatty acid CL (i.e., mean carbon number per fatty acid) and total UN (i.e., mean double bonds per fatty acid) of milk fat directly from a MIR spectra of milk at $40^{\circ} \mathrm{C}$ and then determine the feasibility of using those measures as real-time correction factors to improve the accuracy of classical MIR fat A and fat B measures of fat content using optimized virtual filters.

\section{MATERIALS AND METHODS}

\section{Experimental Design and Statistical Analysis}

Two hundred sixty-eight milks were selected from a total population of 201 individual farm milks, 29 individual cow milks, and 18 sets (14 milks per set) of modified milk calibration samples (Kaylegian et al., 2006). Modified milk calibration samples were produced as described by Kaylegian et al. (2006) using the general procedure described by the International Dairy Federation (IDF, 2000) with a modification to increase the range of lactose concentrations in the calibration sample set. Within the 268 samples, there were 3 sub-populations: modified milks (18 sets of 14 samples per set), individual farm bulk milks $(\mathrm{n}=190)$, and individual cow milks $(\mathrm{n}=29)$. The bulk tank milks used in the modeling were from different regions of the United States from farms feeding a wide range of diets and using various commercial rumen bypass fat supplements. The individual cow milks represented different 
stages of lactation. All milks used in the calibration had reference chemistry values for fat, true protein, and anhydrous lactose. Fat was extracted from each milk, the milk fat was saponified, and the free fatty acids (FFA) produced by the saponification were converted to FAME and quantified using GLC. Mean fatty acid CL and UN were calculated based on GLC data (Kaylegian, et al., 2009a). A MIR spectrum was collected for each milk. The spectra from all milks were analyzed using PLS regression analysis with Grams A/I PLSIQ Version 7.00 software (Thermo Fisher Scientific Inc., Waltham, MA) to develop PLS prediction models for fatty acid CL and total UN of milk fat. The accuracy of the fatty CL and UN PLS prediction models was determined using a set of 47 bulk tank milks that were not part of the population of milks used to develop the models.

The data output from the MIR spectrophotometer using real-time measures of $\mathrm{CL}$ and $\mathrm{UN}$ was used to correct the fat $\mathrm{A}$ and fat $\mathrm{B}$ measures (of fat content) for sample-to-sample variation in fatty acid composition to determine if these corrections would improve accuracy of fat prediction in comparison with chemical reference values from each milk. This was done over a period of 5 mo with 12 sets of 10 individual farm milks that were not a part of the PLS modeling sample population or the PLS model validation milks.

\section{Selection and Characteristics of Milk Sample Population Used for PLS Modeling}

Each subpopulation of milks brought a different strength to the overall population of samples used to develop the PLS models. The 18 sets of modified milk calibration samples, 14 milks per set, formed a base of samples with a large and orthogonal variation in fat, true protein, and anhydrous lactose concentration within each set but with constant fatty acid composition within the set. There was set-to-set variation in fatty acid composition within this sub-population of milks, whereas within each set of 14 samples the fatty acid composition was the same but the level of fat varied systematically from sample to sample over the range from about 0.2 to $5.8 \%$ fat (Kaylegian et al., 2006). We did not want the number of modified milk samples to have too much influence on the PLS model development because the variation in the modified milk fatty acid composition from set to set was small relative to the sample-to-sample variation in the individual farm and cow milks. For this reason only 3 sample spectra per modified milk set were retained in the calibration set (i.e., in total 49 spectra out of 252 sample spectra available from the 18 sets). Selection was through inclusion of each 5th sample spectrum from each modified milk, arbitrarily starting at the third sample of set 1 , thereby retaining orthogonality and variation among distributions in fat, true protein, and anhydrous lactose for the selected sample spectra. The farm bulk tank milks were from different regions (Texas, Kansas, Ohio, and New Hampshire) of the United States and individual cow milks were from the Cornell University (Ithaca, NY) dairy herd.

\section{Milk Component Analysis}

Reference chemistry values for all milks were determined in duplicate using the following validated methods (AOAC International, 2000): fat by modified Mojonnier ether extraction (method 989.05), true protein by Kjeldahl analysis (method 991.22), and anhydrous lactose by enzymatic analysis (method 2006.06). For the modified milk calibration samples, the chemical reference values for fat, protein, and lactose were all-laboratory mean reference values (Kaylegian et al., 2006). The all-laboratory mean values were based on the average results of 10 to 12 laboratories with statistical outliers removed using the Cochran, and single and double Grubbs outlier procedures used in collaborative studies of method performance (AOAC, 1989; AOAC International, 1995), as described by Wojciechowski et al. (2016).

\section{Fatty Acid Analysis}

Fat Extraction. Milk samples in $60-\mathrm{mL}$ plastic vials (Capitol Plastic Products, Amsterdam, NY) were heated to $40^{\circ} \mathrm{C}$ to ensure uniform dispersion of the fat within the sample. After inverting the vial 10 times to mix, a 10-g test portion of milk was weighed to nearest $0.1 \mathrm{mg}$ into a Mojonnier flask (Forcoven Products Inc., Humble, TX). The complete description of the Mojonnier ether extraction method was reported by Barbano et al. (1988). To each flask, 3 drops of phenolphthalein indicator $(0.5 \% \mathrm{wt} / \mathrm{vol}$ in ethanol) and $1.5 \mathrm{~mL}$ of ammonium hydroxide (concentrated, ACS grade, specific gravity 0.9 ) were added and shaken for $15 \mathrm{~s}$. Three extractions (first extraction: 10, 25, and $25 \mathrm{~mL}$; second extraction: 5, 15, and $15 \mathrm{~mL}$; and third extraction 0 , 15 , and $15 \mathrm{~mL}$ of ethanol, diethyl ether, and petroleum ether, respectively) were carried out on each sample. The ether and fat mixture from each extraction (top clear portion of liquid) was carefully decanted into a weighed clean, dry aluminum pan and the solvent was evaporated at $60^{\circ} \mathrm{C}$. The pan plus fat was weighed to determine the weight of fat extracted. The fat was transferred from the pan into a hexane rinsed screw-cap glass bottle (Qorpak, $30 \mathrm{~mL}$ borosilicate glass, VWR Scientific, West Chester, PA) with two 10-mL rinses of 
2:1 (vol/vol) chloroform:methanol and stored protected from light at $-20^{\circ} \mathrm{C}$. All glassware used for methylation and GLC was rinsed with hexane before use.

Fatty Acid Methylation. The target amount of fat needed for methylation of each milk was $0.0333 \mathrm{~g}$. The weight of fat extracted was used to calculate the amount of fat per milliliter in the chloroform:methanol mixture and that amount of the mixture was added to the methylation flask (25-mL pear-shaped 14/20 standard taper flask). A stream of dry nitrogen was used to evaporate the chloroform:methanol to leave only the fat portion that was saponified and methylated (Barbano and Sherbon, 1980; Lynch et al., 1992). The flask was attached to a $200-\mathrm{mm} 14 / 20$ standard taper refluxing condenser and lowered into a $100^{\circ} \mathrm{C}$ sand bath. Two milliliters of $0.5 \mathrm{~N}$ methanolic potassium hydroxide was immediately added through the top of the condenser, and contents were allowed to boil and reflux for 6 min before $2 \mathrm{~mL}$ of $12 \%$ methanolic boron trifluoride was added in the same manner. After 2 min of boiling, $4.8 \mathrm{~mL}$ of hexane was added through the top of the condenser and allowed to boil for $1 \mathrm{~min}$. The flask was raised out of the sand bath until boiling ceased, was detached from the condenser, and $6 \mathrm{~mL}$ of room temperature saturated $\mathrm{NaCl}$ solution was added. The pear-shaped flask was stoppered with a 14/20 standard taper ground glass stopper; the contents were mixed using a vortex mixer for $10 \mathrm{~s}$ and allowed to stand at room temperature until the aqueous and hexane layers separated (about $10 \mathrm{~min}$ ). Saturated $\mathrm{NaCl}$ solution was added to the flask to bring the hexane layer into the neck, and this layer was transferred to a screw-top borosilicate glass test tube $(16 \mathrm{~mm} \times 125 \mathrm{~mm})$ using a borosilicate glass Pasteur pipette. Four milliliters of saturated $\mathrm{NaCl}$ solution was added to the test tube, then capped and mixed with a vortex mixer for $10 \mathrm{~s}$ and allowed to sit for $10 \mathrm{~min}$. A portion of the hexane layer was transferred to a $1-\mathrm{mL}$ borosilicate glass serum vial (\#223682, Wheaton, Millville, NJ) containing $0.065 \mathrm{~g}$ of anhydrous sodium sulfate to absorb residual moisture. An 11-mm aluminum crimp-top seal with a Teflon-faced rubber septa (National Scientific Co., Lawrenceville, GA) was placed over the vial. Vials were stored at $-15^{\circ} \mathrm{C}$ protected from light until GLC analysis.

Quantitative Fatty Acid Recovery Standard. A quantitative FFA standard was prepared and a combined recovery-detector response factor for each fatty acid was determined. The quantitative standard was prepared by weighing (to 5 decimal places) individual FFA (even carbon numbers 4:0 to 14:0; 14:1 cis; 15:0; 16:0; $16: 1$ cis $; 17: 0 ; 18: 0 ; 18: 1$ trans $-9 ; 18: 1$ trans- $11 ; 18: 1$ cis-9; 19:0; 18:2 cis-9, cis-12; 20:0; 18:3 cis-9, cis-12, cis-15; 18:2 cis-9 trans-11; 18:2 trans-10 cis-12. Alltech
Associates Inc., Deerfield, IL) into a $50-\mathrm{mL}$ volumetric flask to produce a quantitative recovery standard with a fatty acid composition similar to milk fat. The FFA were weighed out in order starting with the longest chain fatty acid and ending with the shortest chain fatty acid. Then a 50-mL volumetric flask was tared and approximately $50 \mathrm{~mL}$ of diethyl ether was added. The total weight of FFA in approximately $50 \mathrm{~mL}$ of diethyl ether was $0.499 \mathrm{~g}$. The relative percentage by weight of each FFA in the mixture was calculated. A 1.1-mL portion of this FFA standard in diethyl ether was methylated (as described above) and analyzed using the same conditions as for a milk fat sample except there was no evaporation step (to avoid loss of volatile short-chain fatty acids) to remove the diethyl ether before methylation. In addition, the hexane used to extract the FAME from the reaction mixture at the end of methylation was reduced from 4.8 to $2.4 \mathrm{~mL}$ for the FFA standard. Three separate methylations of the FFA standard were done and 3 GLC injections were made for each methylation. The mean area percent for each fatty acid from the 9 injections of the methylated FFA standard was used to calculate the recovery factor for each fatty acid. These recovery factors were used to convert from relative area percent to weight percent for milk fat samples. Integration was performed with the Hewlett Packard Chemstation (Rev. A04.02) standard integrator software.

FAME Analysis by GLC. Test portions of FAME in hexane were analyzed by GLC using a Varian CPSIL88 capillary column $(100 \mathrm{~m} \times 0.25 \mathrm{~mm} \times 0.2 \mu \mathrm{m}$ film thickness, ID code \#CP7489; Varian Inc., Lake Forest, CA), installed in a Hewlett Packard 6890 GC System equipped with an automatic liquid sampler and a flame ionization detector (Hewlett Packard Co., Wilmington, DE). The temperature at the split inlet was $250^{\circ} \mathrm{C}$ and the split ratio was 100:1. The helium carrier gas was at a constant flow rate of $1 \mathrm{~mL} / \mathrm{min}$. A $1-\mu \mathrm{L}$ injection of test portion or $3 \mu \mathrm{L}$ of standard was analyzed under temperature programmed conditions with an initial column oven temperature of $80^{\circ} \mathrm{C}$ and held for $5 \mathrm{~min}$, increased at $4.0^{\circ} \mathrm{C} / \mathrm{min}$ to $160^{\circ} \mathrm{C}$, increased to $1.0^{\circ} \mathrm{C} / \mathrm{min}$ to $175^{\circ} \mathrm{C}$, increased at $0.50^{\circ} \mathrm{C} /$ min to $190^{\circ} \mathrm{C}$, and held for $5.0 \mathrm{~min}$. After all FAME had eluted from the column, the temperature was increased at $10.0^{\circ} \mathrm{C} / \mathrm{min}$ to $220^{\circ} \mathrm{C}$ and held for $8.0 \mathrm{~min}$ to elute higher molecular weight compounds. The column was cooled to $80^{\circ} \mathrm{C}$ and stabilized before injection of the next sample.

Calculation of Fatty Acid Chain Length and Unsaturation. The area percent values for each fatty acid in the chromatogram were corrected for their individual recovery using the quantitative standard and recover factors described above. Next, the following se- 
ries of calculations were done. The individual recovery adjusted FAME were normalized to a sum of $100 \%$ for the known FAME in each sample. The adjusted FAME data were converted to a fatty acid basis by multiplying by a correction factor (molecular weight of each fatty acid divided by the molecular weight of its FAME) to remove the molecular weight of the methyl ester group for each fatty acid, and were then normalized to a sum of $100 \%$ to obtain the relative fatty acid composition based on the fatty acids not FAME. The relative fatty acid composition was used to calculate the mean fatty acid CL and UN by converting each fatty acid to a millimolar basis and weighting each fatty acid by multiplying by either the number of carbons or the number of double bonds in the fatty acid chain, respectively. The mean fatty acid CL (expressed as carbon number) was calculated by dividing the total fatty acid concentration weighted for carbon number by the total fatty acid concentration. The mean UN (expressed as double bonds per fatty acid) was calculated by dividing the total fatty acid concentration weighted for the number of double bonds by the total fatty acid concentration. An example of the complete calculation is provided in Kaylegian et al. (2009a).

MIR Milk Analysis. Fourier transform MIR milk analyses were performed with a LactoScope FT infrared (FTIR) milk analyzer (model FT 400, Delta Instruments, Drachten, the Netherlands) equipped with a Work-IR optical bench (ABB Bomem, Montreal, Canada), a standard $\mathrm{CaF}_{2}$ cuvette $(23 \mu \mathrm{m})$ using a fixed virtual filter calibration approach. The virtual filter sample and reference center wavelengths and bandwidths used for fat $\mathrm{B}$, fat $\mathrm{A}$, protein, and lactose were those reported in a previous study (Kaylegian et al., 2009b). Sample center wavelengths used for fat B, fat A, protein, and lactose were $2,851 \mathrm{~cm}^{-1}(3.508 \mu \mathrm{m}), 1,748$ $\mathrm{cm}^{-1}(5.721 \mu \mathrm{m}), 1,541 \mathrm{~cm}^{-1}(6.489 \mu \mathrm{m})$, and 1,048 $\mathrm{cm}^{-1}(9.542 \mu \mathrm{m})$, and the reference wavelengths were $2,812 \mathrm{~cm}^{-1}(3.556 \mu \mathrm{m}), 1,791 \mathrm{~cm}^{-1}(5.583 \mu \mathrm{m}), 1,491$ $\mathrm{cm}^{-1}(6.707 \mu \mathrm{m})$, and $1,293 \mathrm{~cm}^{-1}(7.734 \mu \mathrm{m})$, respectively, using the bandwidths indicated by Kaylegian et al. (2009b). The LactoScope was precalibrated according to the procedures described by Lynch et al. (2006), and was calibrated with modified milks (Kaylegian et al., 2006) on the day the individual farm milks were analyzed. The corrected fat estimates were calculated using the calibration equations described by Kaylegian et al. (2006) and the intercorrection factors determined by the method of Kaylegian et al. (2009b). The LactoScope FTIR was equipped with the FTIRScope and DataScope software from Delta Instruments, and the IR-QC software (Lynch et al., 2006; Kaylegian et al., 2009a) developed at Cornell University. This approach was used to obtain a MIR traditional filter model pre- dicted fat, true protein, and anhydrous lactose values for each milk. For collection of the MIR spectra for milk samples, the LactoScope FTIR was operated at a spectral resolution of $8 \mathrm{~cm}^{-1}$ (digital resolution of $3.85 \mathrm{~cm}^{-1}$ ) collecting averages of 6 scans per analysis (corresponding to 400 samples/hour, using standard double-sided forward-backward interferogram acquisition, cosine apodization, and phase correction for Fourier transformation yielding an energy spectrum). The average of 6 scans was transformed into an absorption spectrum by calculation of the $1 / \log$ ratio with reference to the spectrum of zero liquid (demineralized water containing $0.01 \%$ triton) and storing the absorption spectrum for milk. These spectra in combination with the GLC reference values for fatty acid composition were analyzed using the PLS routines of the GRAMS PLSIQ Version 7.0 software (Thermo Fisher Scientific Inc., Waltham, MA) to calculate the $\beta$ coefficients for PLS calibration models designed to predict various aspects of fatty acid composition based on the MIR spectra of milk samples.

\section{Statistical Analysis of Spectral Data}

Removal of Outlier Data. Of the total 201 farm milk samples, 11 were removed, which were obvious outliers with regard to predicted fat. Nine of these 11 milks were concentration outliers, for which differences between estimated and reference values were not $< \pm 0.2 \% \mathrm{~m} / \mathrm{m}$. The 2 other samples were spectral outliers for which spectral residuals exceeded the average in spectral residuals calculated over all samples by a factor of 13 for one sample and 140 for the other.

Calculation of PLS Models. The PLS models for prediction of fatty acid CL (expressed as carbon number per fatty acid) and total UN (expressed as double bonds per fatty acid) were calculated using the spectral ranges $(3,000$ to $2,750,1,800$ to 1,700 , and 1,580 to $\left.1,000 \mathrm{~cm}^{-1}\right)$, applying mean centering of the data and 2 -point baseline correction relative to average absorbance calculated over wavelength ranges of 2,650 to $2,550 \mathrm{~cm}^{-1}$ and 1,260 to $1,200 \mathrm{~cm}^{-1}$. Cross-validation (cyclic leaving out 1 sample at a time) was applied for determining the number of factors used for each model. Spectral and concentration outlier samples (11 out of 279) were identified based on Mahalanobis distances and removed from the data set and then the PLS modeling was repeated with outliers removed. The number of factors selected for each final prediction model was the number of factors that produced an F-test predicted residual sum of squares (FPRESS) of between 1 and 0.75, which will be near the minimum standard error of cross-validation (SECV). Adding more factors to the model starts modeling in noise and may increase the 
SECV. The PLS models for individual fatty acids and groups of fatty acids (to be reported in another publication) were developed, in addition to models for fat, true protein, and anhydrous lactose. The PLS model developed from this data set for direct prediction of total milk fat had a validation performance in comparison to ether extraction (method 989.05; AOAC International, 2000) and was similar to basic optimized filter models (Kaylegian et al., 2009b) using a 70\% fat B and 30\% fat A blend of results and was not evaluated further.

\section{Performance Validation of PLS Models}

Validation of the performance of the fatty acid CL and UN models was conducted with 47 individual farm bulk tank milks (from Texas, Vermont, and Ohio) that were not part of the population of milks used to develop the PLS prediction models. Each milk was analyzed by the GLC reference method and the FT 400 LactoScope MIR milk analyzer as described above, and a value for each sample for CL and UN was produced. The mean difference (MD), standard deviation of the difference (SDD), and relative standard deviation (RSD) of the difference (i.e., coefficient of variation) were calculated for CL and UN.

\section{Using Measured Chain Length and Unsaturation to Improve Accuracy of Fat Testing}

There was positive coefficient of determination $\left(\mathrm{R}^{2}\right.$ $=0.85$ ) of fatty acid CL (i.e., mean carbon number per fatty acid) and UN (i.e., mean double bonds per fatty acid) in populations of bulk tank milks (data not shown). Variation in fatty acid CL is reflected in the fat $\mathrm{B}$ measure $(\mathrm{C}-\mathrm{H}$ stretch$)$ of fat, but not in fat $\mathrm{A}(\mathrm{C}=\mathrm{O})$ stretch, causing error in the fat A measure. Conversely, variation in UN of fatty acids only has a small effect on fat A measures, but causes larger errors in fat B measures of fat content of milk (Kaylegian et al., 2009b). To overcome these weaknesses, we developed separate PLS models to measure the CL and UN of fatty acids in each milk sample and then used those values in real time to correct the fat B and fat A measures of milk fat during testing. It is normal practice for fat $\mathrm{A}$ and fat $\mathrm{B}$ measures to be corrected for background variation in anhydrous lactose and true protein content of each milk sample, as described previously (Barbano and Clark, 1989, Lynch et al., 2006). In the present study, we applied additional linear intercorrection factors for variation in fatty acid CL and UN to the fat A and B measures of fat as each sample was measured, using an equation of the same form described by Barbano and Clark (1989). The first of the 12 sets of individual farm milk samples was used to adjust the slope and intercept of the fat $\mathrm{A}$ and fat $\mathrm{B}$ values intercorrected (for lactose, protein, CL, and UN) signal and was designated as set 1 . The testing was done with a Lactoscope FTA (Delta Instrument) with a $36-\mu \mathrm{m}$ cuvette path length with a BMX FTIR optical bench (ABB Bomem, Montreal, Canada). To do this, the PLS models developed for the $23-\mu \mathrm{m}$ cuvette were transformed to work on an optical system with a $36-\mu \mathrm{m}$ cuvette path length. The Lactoscope FTA was set up with fat A and fat B basic filter models using optimized filter wavelengths and intercorrection factors as described by Kaylegian et al. (2009b). Primary slopes of uncorrected fat A and fat B signals were set using primary slope samples as described by Barbano and Clark (1989) and Lynch et al. (2006) using the "scale" parameter for each filter in the Delta FTA software. The scale value for fat A was 22.17 and for fat B was 34.81. The intercorrection factors for lactose and protein on fat B and fat A were similar to those reported by Kaylegian et al. (2009b). No linearity adjustment was needed. The slope and intercept of the intercorrected values for fat A and B were adjusted monthly using modified milk calibration milks (Kaylegian et al., 2006) during the study. The corrected fat A and fat B values were further corrected for sample-to-sample variation in fatty acid CL, and UN using the derived component calculation capability of the Lactoscope FTA was used to add the linear corrections for CL and UN. After that, 11 more sets of 10 farm milks each were tested over a 6 -mo period to validate the accuracy of the correction. Each milk in the 11 additional sets was tested in duplicate for fat by ether extraction (AOAC International, 2000; method 989.05). Fat content of individual milks ranged from about 2.9 to $5.25 \%$ fat. No adjustments of slope or intercept were made for any of the fat predictions by MIR beyond the adjustment made on set 1 . Fat test results (fat $\mathrm{A}$, fat $\mathrm{B}, 70 \%$ fat $\mathrm{B}+30 \%$ fat $\mathrm{A}$, fat $\mathrm{A} C \mathrm{CL}$ corrected, fat A CL and UN corrected, and fat B UN corrected) were produced for all 12 sets of 10 samples each and compared with ether extraction results by calculation of MD and SDD for each type of fat measure for each set of 10 milks. Euclidean distance (ED) was calculated (square root of the sum of the square of the MD and SDD) for each different method of fat prediction. A comparison of agreement with ether extraction results was done using ED.

\section{RESULTS AND DISCUSSION}

\section{PLS Model Description for Fatty Acid Chain Length Prediction}

A 9-factor PLS model was selected as the optimum model for prediction of fatty acid CL expressed as car- 


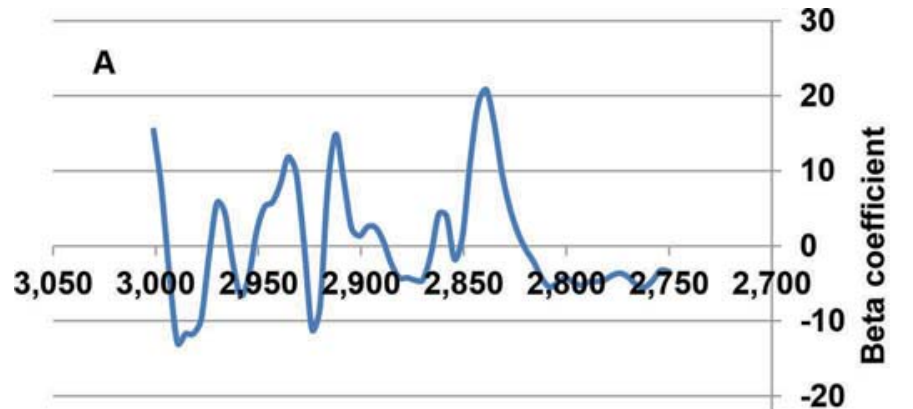

Wave number $\left(\mathrm{cm}^{-1}\right)$

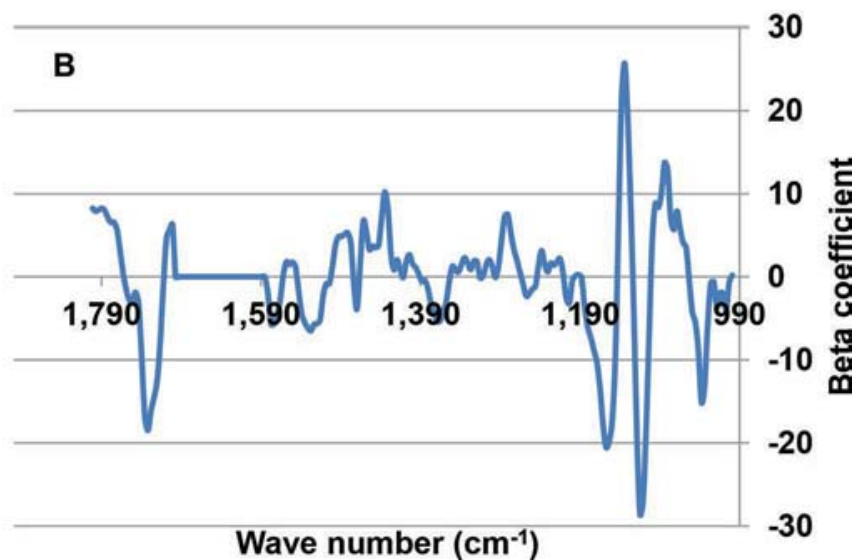

Figure 1. Beta coefficient plots as a function of wave number $\left(\mathrm{cm}^{-1}\right)$ for the 9-factor prediction model for fatty acid chain length (expressed as carbon number per fatty acid) in wave number range (A) 3,000 to $2,750 \mathrm{~cm}^{-1}$ and (B) 1,800 to $1,000 \mathrm{~cm}^{-1}$. Color version available online.

bon number per fatty acid, with calculations of carbon number per fatty acid done as described by Kaylegian et al. (2009a). The characteristics of the population of milks used (i.e., number of samples, mean, SD, minimum, and maximum) for model development and SECV, $\mathrm{R}^{2}$ of cross-validation, F-ratio, F-test, and ratio of standard error of cross-validation to standard deviation (RPD) are shown in Table 1 . The $\beta$-coefficients for the PLS model for prediction of fatty acid CL are shown as a function of wave number in Figure 1.

\section{PLS Model Description for Fatty Acid Unsaturation Prediction}

A 10-factor PLS model was selected as the optimum model for prediction of fatty acid UN expressed as double bonds per fatty acid, with calculations done as described by Kaylegian et al. (2009a). The characteristics of the population of milks used (i.e., number of samples, mean, SD, minimum, and maximum) for model development and SECV, $\mathrm{R}^{2}$ of cross-validation,
F-ratio, F-test, and RPD are shown in Table 1. The $\beta$-coefficients for the PLS model for prediction of fatty acid UN are shown as a function of wave number in Figure 2.

\section{Performance Validation of PLS Models for Chain Length and Unsaturation}

The MD and SDD for the validation comparison of MIR and GLC estimates of fatty CL and UN are shown in Table 2. The range of CL was from 14.00 to 14.84 carbons per fatty acid and the range of UN was from 0.23 to 0.40 double bonds per fatty acid in the 47 milks. There was excellent agreement of GLC and IR estimates of fatty acid CL expressed as mean carbon atoms per fatty acid (14.47 vs. 14.53, respectively), with a RSD of $0.43 \%$. A method with a RSD less than $1 \%$ is considered an excellent method from an analytical perspective (Horwitz and Albert, 2006). The linear regression equation for reference and predicted values for fatty acid CL was $y=0.916 x+1.161$, where $y=$ GLC reference and $\mathrm{x}=$ predicted and the $\mathrm{R}^{2}$ was 0.93 . There was good agreement between GLC and IR estimates of fatty acid UN (0.319 vs. 0.321 double bonds per fatty acid, respectively), with a RSD of $3.29 \%$. The linear regression equation for reference and predicted values for fatty acid UN was $\mathrm{y}=0.913 \mathrm{x}+0.025$, where $\mathrm{y}=$ GLC reference and $\mathrm{x}=$ predicted and the $\mathrm{R}^{2}$ was 0.94 . When the absolute value of a measured component is very low, the RSD values are generally higher because

Table 1. Number of samples, mean of reference values, SD, minimum and maximum values of final population of samples (i.e., with outliers removed) used to develop partial least squares (PLS) prediction models $^{1}$

\begin{tabular}{lcc}
\hline & \multicolumn{2}{c}{ MIR PLS prediction models } \\
\cline { 2 - 3 } Parameter & Chain length & Unsaturation \\
\hline Number of samples & 268 & 268 \\
Mean & 14.55 & 0.33 \\
SD & 0.24 & 0.04 \\
Minimum & 13.95 & 0.22 \\
Maximum & 15.43 & 0.047 \\
Number of factors & 9 & 10 \\
SECV & 0.112 & 0.012 \\
R $^{2}$ CV & 0.78 & 0.90 \\
F-ratio (PRESS) & 1.07 & 1.10 \\
F-test (FPRESS) & 0.70 & 0.78 \\
RPD & 2.1 & 3.3 \\
\hline
\end{tabular}

${ }^{1}$ Number of factors, standard error of cross-validation (SECV), $\mathrm{R}^{2}$ of cross-validation $\left(\mathrm{R}^{2} \mathrm{CV}\right)$, F-ratio predicted residual sum of squares (PRESS), F-test (FPRESS), and ratio of standard deviation to standard error of cross-validation (RPD) of the calibration step for the PLS model to predict fatty acid chain length expressed as number of carbons per fatty acid and fatty acid unsaturation expressed as double bonds per fatty acid. MIR = mid-infrared. 
Table 2. Comparison of mean chain length (carbons per fatty acid) and mean unsaturation (double bonds per fatty acid) by GLC reference values versus mid-infrared (MIR) predicted values for 47 independent validation milks from individual farms located in different regions of the United States

\begin{tabular}{|c|c|c|c|c|c|c|}
\hline Parameter & \multicolumn{3}{|c|}{ Chain length } & \multicolumn{3}{|c|}{ Unsaturation } \\
\hline SD of difference & & & 0.063 & & & 0.010 \\
\hline Relative SD (\%) & & & 0.433 & & & 3.295 \\
\hline Minimum value & 14.004 & 13.942 & & 0.236 & 0.214 & \\
\hline
\end{tabular}

even a small RSD can be a higher percentage of the mean concentration for low concentration components.

\section{Use of Chain Length and Unsaturation Data to Correct MIR Fat A and Fat B}

The fatty CL and UN predicted values from the PLS models had a secondary slope and intercept adjustment made using GLC reference values for CL and UN on the first set of 10 milks that were analyzed and then these slope and intercepts were not adjusted again during the 6-mo period of the study. The fat A was corrected for sample-to-sample variation in CL and UN using the following equation: slope and intercept adjusted fat $\mathrm{A}$ corrected for protein and lactose minus $\{[(-0.1756 \times$ $\mathrm{CL})+2.5591]+(0.16 \times \mathrm{UN})+0.0452\}$. The fat $\mathrm{B}$ was corrected for sample-to-sample variation in UN using the following equation: slope and intercept adjusted fat $\mathrm{B}$ corrected for protein and lactose minus $[(-0.1422 \times$ $\mathrm{UN})+0.073$. The CL per fatty acid varied from 13.8 to 14.65 carbons and the double bonds per fatty acid varied from 0.17 to 0.32 double bonds across the samples in the 12 sets of 10 milks each (data not shown).

Kaylegian et al. (2009a) reported that sample-tosample differences between ether extraction reference values and MIR predicted fat values were caused by variation in fatty acid composition among samples. Kaylegian et al. (2009b) reported that sample-to-sample variation in UN caused deviations in fat B results from reference values, whereas variation in CL caused deviations in fat A measures. Therefore, the real-time predictions of fatty CL and UN for each sample were used to correct for these variations. The results of the method performance evaluation are presented in Table 3. As expected, the ED values for fat A were about twice those for fat B $(P<0.05)$. For this population of validation samples the fat $B$ alone had a smaller $E D$ from reference ether extraction values than the blend of $70 \%$ fat B corrected and $30 \%$ fat A corrected. In a validation study on a different population of milks reported by Kaylegian et al. (2009a), the combination of fat $\mathrm{A}$ and $\mathrm{B}$ was more accurate than fat $\mathrm{B}$ alone. Biggs and McKenna (1989) made a similar observation. The correction of fat $\mathrm{B}$ for variation in UN decreased $(P<0.05)$ the ED by 0.0064 from 0.0339 to 0.0275 , as hypothesized by Kaylegian et al. (2009a). The correction of fat A for sample-to-sample variation in CL made the largest improvement $(P<0.05)$ of fat A (from 0.0722 to 0.0184$)$ with a further small improvement $(P$

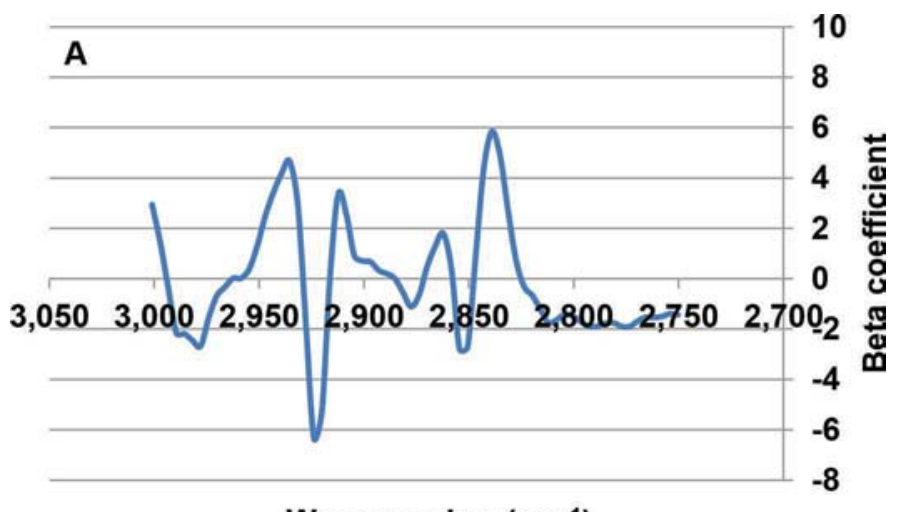

Wave number $\left(\mathrm{cm}^{-1}\right)$

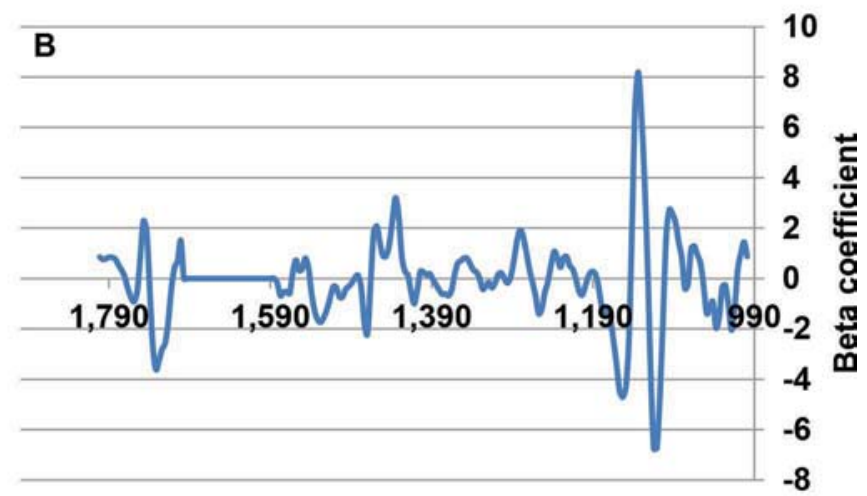

Wave number $\left(\mathrm{cm}^{-1}\right)$

Figure 2. Beta coefficient plots as a function of wave number $\left(\mathrm{cm}^{-1}\right)$ for the 10-factor prediction model for fatty acid unsaturation (expressed as double bonds per fatty acid) in the wave number range (A) 3,000 to $2,750 \mathrm{~cm}^{-1}$ and (B) 1,800 to $1,000 \mathrm{~cm}^{-1}$. Color version available online. 
Table 3. Euclidean distance (ED) values for fat A ( $\mathrm{C}=\mathrm{O}$ stretch), fat B (C-H stretch), $70 \%$ fat B plus $30 \%$ fat A, fat A chain length (CL) corrected, fat A with CL and unsaturation (UN) correction, fat B with UN correction, and mean difference (MD) and standard deviation of the difference (SDD) for fat A with correction for CL and UN for 12 sets of 10 farm milks each, analyzed by ether extraction, mid-infrared, and GLC

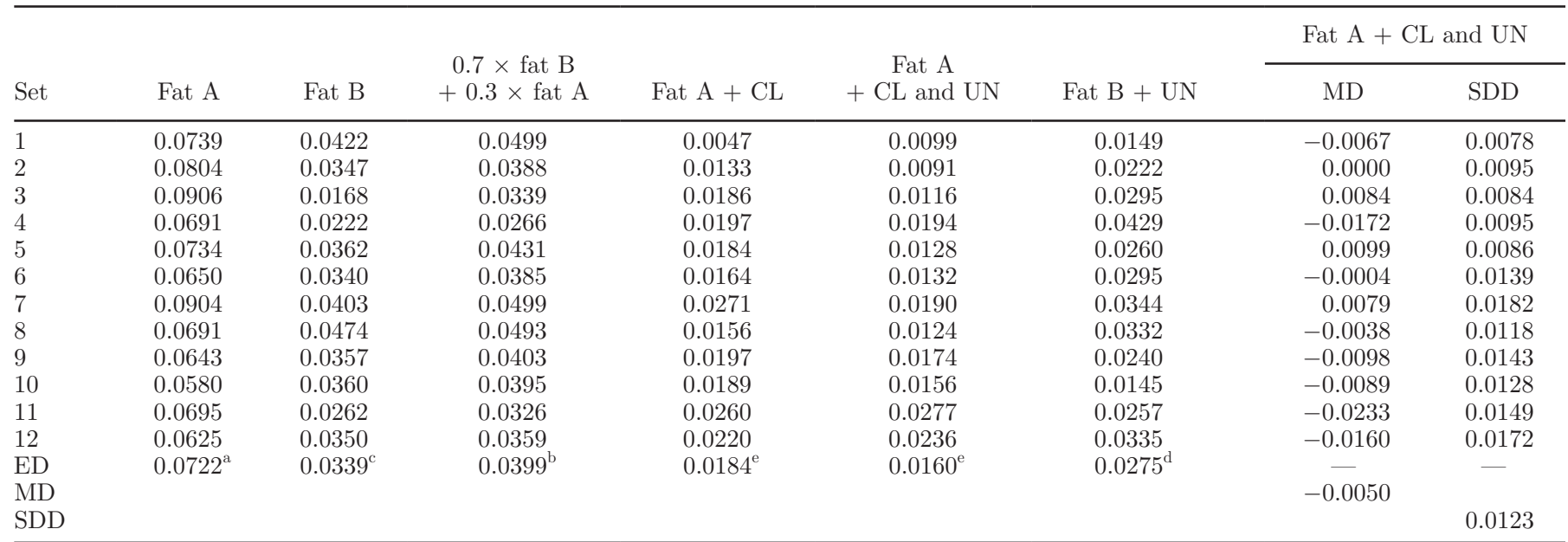

${ }^{\mathrm{a} e}$ Mean ED in same row not sharing a common superscript differ $(P<0.05)$.

$<0.05)$ achieved by a correction for both CL and UN (from 0.0184 to 0.0160). The MD and SDD between the fat A adjusted for CL and UN compared with ether extraction reference values for each set of 10 samples is shown in Table 3 . The validation data in Table 3 provide evidence that there was additional information in the IR spectra that could be used to improve the accuracy of fat prediction. It is interesting to note that a PLS model for direct measurement of fat developed using the same data set was not able to achieve this accuracy. It is possible that this may be due to variation of glycerol as a percent of triglyceride molecular weight that results from the wide range of triglyceride carbon number (C24 to C54) in milk fat (Barbano and Sherbon, 1980). The fact that the use of PLS to predict fat directly did not improve the accuracy of fat prediction over traditional filter models in the current study is consistent with the report by Luinge et al. (1993) that a PLS model to directly predict fat from the spectra did not perform better than a traditional filter model. This would suggest that there is something in correlations among various parameters in the modeling population of spectra that prevents the PLS modeling approach from producing a more accurate model when trying to predict fat directly, as indicated by Kaylegian et al. (2009a).

\section{CONCLUSIONS}

Partial least square regression models for predicting the average CL (carbons per fatty acid) and UN (double bonds per fatty acid) of fatty acid in the fat portion of milk from MIR milk spectra were developed and validated. This is unique in that fat concentration independent characteristics of fat structure were accurately predicted directly with transmission MIR analysis of milk. The validation performance of the prediction model for CL produced a RSD of $0.43 \%$ for CL and $3.3 \%$ for UN. The correction of a traditional fat B virtual filter result $(\mathrm{C}-\mathrm{H}$ stretch) for sample-to-sample variation in UN reduced the ED for predicted fat from 0.034 to 0.025 . The correction of a traditional fat $\mathrm{A}$ virtual filter result $(\mathrm{C}=\mathrm{O}$ stretch $)$ modified with additional information on sample-to-sample variation of CL and UN gave the largest improvement (reduced ED from 0.072 to 0.016 ) and the best validation accuracy (i.e., lowest ED) of all the fat prediction methods.

\section{ACKNOWLEDGMENTS}

The authors thank the USDA Federal Milk Markets (Carrollton, TX), the Northeast Dairy Foods Research Center (Ithaca, NY), and Delta Instruments (Drachten, the Netherlands) for partial funding of this research. The technical assistance of Jessica Mallozzi, Maureen Chapman, and Chassidy Coon of Cornell University and Evert de Jong of Delta Instruments was greatly appreciated.

\section{REFERENCES}

AOAC. 1989. Guidelines for collaborative study procedure to validate characteristics of a method of analysis. J. AOAC 72:694-704.

AOAC International. 1995. Guidelines for collaborative study procedure to validate characteristics of a method of analysis. J. AOAC 78:143A-160A.

AOAC International. 2000. Official Methods of Analysis. 17th ed. Association of Official Analytical Chemists, Gaithersburg, MD. 
Barbano, D. M., and J. L. Clark. 1989. Infrared milk analysis: Challenges for the future. J. Dairy Sci. 72:1627-1636.

Barbano, D. M., J. L. Clark, and C. E. Dunham. 1988. Comparison of the Babcock and ether extraction methods for determination of fat content of milk: Collaborative study. J. AOAC 71:898-914.

Barbano, D. M., and J. M. Lynch. 2006. Major advances in testing of dairy products: Milk component and dairy product attribute testing. J. Dairy Sci. 89:1189-1194.

Barbano, D. M., and J. W. Sherbon. 1980. Polyunsaturated protected lipid: Effect on triglyceride molecular weight distribution. J. Dairy Sci. 63:731-740.

Biggs, D. A., G. Johnsson, and L. O. Sjanja. 1987. Analysis of fat, protein, lactose, and total solids by infrared absorption. Pages 21-30 in Rapid Methods for Measurement of the Major Components of Milk. Int. Dairy Fed. Bull. 208. Int. Dairy Fed., Brussels, Belgium.

Biggs, D. A., and D. McKenna. 1989. Alternative methods for infrared analysis of fat in milk: Interlaboratory study. J. AOAC 72:724-734

De Marchi, M., V. Toffanin, M. Cassandro, and M. Pensa. 2014. Invited Review: Mid-infrared spectroscopy as a phenotyping tool for milk traits. J. Dairy Sci. 97:1171-1186.

Ferrand-Calmels, M., I. Palhière, M. Brochard, O. Leray, J. M. Astruc, M. R. Aurel, S. Barbey, F. Bouvier, P. Brunscwhig, H. Caillat, M. Douguet, F. Faucon-Lahalle, M. Gelé, G. Thomas, J. M. Trommenschlager, and H. Larroque. 2014. Prediction of fatty acid profiles in cow, ewe, and goat milk by mid-infrared spectrophotometry. J. Dairy Sci. 97:17-35.

Horwitz, W., and R. Albert. 2006. The Horwitz ratio (HorRat): A useful index of method performance with respect to precision. J. AOAC Int. 89:1095-1109.

International Dairy Federation. 2000. Whole milk. Determination of milk fat, protein, and lactose content. Guidance on operation of mid-infrared instruments. IDF Standard 141C:2000 (Int. Dairy Fed., Brussels, Belgium).

Kaylegian, K. E., D. A. Dwyer, J. M. Lynch, D. E. Bauman, J. R. Fleming, and D. M. Barbano. 2009a. Impact of fatty acid composition on the accuracy of mid-infrared fat analysis of farm milks. J. Dairy Sci. 92:2502-2513.

Kaylegian, K. E., G. E. Houghton, J. M. Lynch, J. R. Fleming, and D. M. Barbano. 2006. Calibration of infrared milk analyzers: Modified milk versus producer milk. J. Dairy Sci. 89:2817-2832.
Kaylegian, K. E., J. M. Lynch, J. R. Fleming, and D. M. Barbano 2009b. Influence of fatty acid chain length and unsaturation on mid-infrared milk analysis. J. Dairy Sci. 92:2485-2501.

Luinge, H. J., E. Hop, E. T. G. Lutz, J. A. van Hemert, and E. A. M. de Jong. 1993. Determination of the fat, protein and lactose content of milk using Fourier transform infrared spectrometry. Anal. Chim. Acta 284:419-433.

Lynch, J. M. 1998. Use of AOAC International method performance statistics in the laboratory. J. AOAC Int. 81:679-684.

Lynch, J. M., D. M. Barbano, D. E. Bauman, G. F. Hartnell, and M. A. Nemeth. 1992. Effect of a prolonged release formulation of $\mathrm{N}$ methionyl bovine somatotropin (sometribove) on production and composition of milk fat. J. Dairy Sci. 75:1794-1809.

Lynch, J. M., D. M. Barbano, J. R. Fleming, and D. Nicholson. 2004 Component testing, the dairy industry, and AOAC International. Inside Laboratory Management: A publication of AOAC International. 8:No.4:24-28.

Lynch, J. M., D. M. Barbano, P. A. Healy, and J. R. Fleming. 1994 Evaluation of Babcock and ether extraction methods: 1989 thru 1992. J. AOAC Int. 77:976-981.

Lynch, J. M., D. M. Barbano, P. A. Healy, and J. R. Fleming. 1997. Performance evaluation of direct forced-air total solids and Kjeldahl total nitrogen methods: 1990 thru 1995. J. AOAC Int. 80:1038-1043.

Lynch, J. M., D. M. Barbano, M. Schweisthal, and J. R. Fleming. 2006. Precalibration evaluation procedures for mid-infrared milk analyzers. J. Dairy Sci. 89:2761-2774.

Soyeurt, H., P. Dardenne, F. Dehareng, G. Lognay, D. Veselko, M. Marlier, C. Bertozzi, P. Mayeres, and N. Gengler. 2006. Estimating fatty acid content in cow milk using mid-infrared spectrometry. J. Dairy Sci. 89:3690-3695.

Wojciechowski, K. L., C. Melilli, and D. M. Barbano. 2016. A proficiency test system to improve performance of milk analysis methods and produce reference values for component calibration samples for infrared milk analysis. J. Dairy Sci. 99:6808-6827. 